\title{
Novel Naturally Occurring Mutations of Enterovirus 71 Associated With Disease Severity
}

\author{
Chih-Shin Chang 1,2, Chun-Che Liao', An-Ting Liou²,3,4, Yi-Chun Chou², Ya-Yen Yü, \\ Chi-Yung Lin ${ }^{5}$, Jen-Shiou Lin ${ }^{5}$, Ching-Shu Suen², Ming-Jing Hwang ${ }^{2}$ and Chiaho Shih ${ }^{2,3 *}$
}

${ }^{1}$ Genomics Research Center, Academia Sinica, Taipei, Taiwan, ${ }^{2}$ Institute of Biomedical Sciences, Academia Sinica, Taipei, Taiwan, ${ }^{3}$ Graduate Institute of Medicine, Kaohsiung Medical University, Kaohsiung, Taiwan, ${ }^{4}$ Drug Development and Value Creation Research Center, Kaohsiung Medical University, Kaohsiung, Taiwan, ${ }^{5}$ Section of Clinical Virology and Molecular

Diagnosis, Department of Laboratory Medicine, Changhua Christian Hospital, Changhua, Taiwan

\section{OPEN ACCESS}

Edited by:

Suh-Chin Wu,

National Tsing Hua University, Taiwan

Reviewed by:

Hiroyuki Shimizu,

National Institute of Infectious

Diseases (NIID), Japan

Li-Min Huang,

National Taiwan University, Taiwan

*Correspondence:

Chiaho Shih

cshih@kmu.edu.tw;

cshih@ibms.sinica.edu.tw

Specialty section:

This article was submitted to

Virology,

a section of the journal

Frontiers in Microbiology

Received: 26 September 2020 Accepted: 21 December 2020

Published: 13 January 2021

Citation:

Chang C-S, Liao C-C, Liou A-T, Chou Y-C, Yu Y-Y, Lin C-Y, Lin J-S,

Suen C-S, Hwang M-J and Shih C

(2021) Novel Naturally Occurring

Mutations of Enterovirus 71

Associated With Disease Severity.

Front. Microbiol. 11:610568.

doi: 10.3389/fmicb.2020.610568
Infection with the re-emerging enterovirus 71 (EV-A71) is associated with a wide range of disease severity, including herpangina, encephalitis, and cardiopulmonary failure. At present, there is no FDA-approved therapeutics for EV-A71. Early diagnosis for the highrisk children is the key to successful patient care. We examined viral genome sequences at the $5^{\prime}$ untranslated region (UTR) and the capsid protein VP1 from 36 mild and 27 severe cases. We identified five EV-A71 mutations associated with severe diseases, including (1) the 5' UTR mutations C580U, A707G, C709U; (2) a VP1 alanine-tothreonine mutation at position 280 (280T), and (3) a VP1 glutamic acid-to-(non-glutamic acid) at position 145 [145(non-E)]. SCARB2 is a known entry receptor for EV-A71. Based on a recent cryoEM structure of the EV-A71-SCARB2 binding complex, VP1280T is near the binding interface between the VP1-VP2 complex and its entry receptor SCARB2. A de novo created hydrogen bonding between the mutant VP1-280T and the VP2-139T, could help strengthen a web-like interaction structure of the VP1-VP2 complex. A stabilized loop turn of VP2, once in contact with SCARB2, can enhance interaction with the host SCARB2 receptor for viral entry. Our findings here could facilitate early detection of severe cases infected with EV-A71 in clinical medicine. In addition, it opens up the opportunity of functional studies via infectious cDNA cloning, site-directed mutagenesis, and animal models in the future.

Keywords: enterovirus 71, EV-A71, disease severity, mutations, VP1, VP2, SCARB2, PSGL-1

\section{INTRODUCTION}

Reemergence of non-polio enterovirus is a new threat to the children (Ho et al., 1999; McMinn, 2002; Cox et al., 2017; Shih et al., 2018). Enterovirus 71 (EV-A71) is closely related to coxsackievirus, poliovirus, and hepatitis A virus (Racaniello, 2006; Feng et al., 2013; Sin et al., 2015). In a recent outbreak of EV-A71 in Shanghai, China, near 1000 deaths of children were reported (Zeng et al., 2012). Infection with EV-A71 is associated with a wide range of disease severity. In mild cases, hand-foot-and-mouth disease (HFMD) is common. In severe cases, it can lead to encephalitis, acute flaccid paralysis, tachycardia, cardiopulmonary failure, and death. Studies in various animal models demonstrated that EV-A71 can target multiple tissues, including the central nerve 
system (Cox et al., 2017; Shih et al., 2018), and recently, the cardiopulmonary system (Chang et al., 2019). Current treatment for EV-A71 remains supportive, and no antivirals are commercially available.

The broad spectrum of disease manifestations is related in part to the differences in host immunity (Liao et al., 2014; Liou et al., 2016, 2019). In addition, it has also been an active research topic whether sequence variation of EVA71 could contribute to the different degrees and tropisms of pathogenesis in vivo. As summarized in Table 1, previous studies reported various viral mutations associated with disease severity in different human cases or mouse models. For example, amino acid 145E of VP1 is the most well documented mutation important for viral replication and pathogenesis in mouse models (Chua et al., 2008; Huang et al., 2012; Chang et al., 2018; Kobayashi et al., 2018; Tee et al., 2019). Similarly, in a monkey model, VP1-145E viruses can induce neurological symptoms, and it was suggested that VP1-145E has a replication advantage for the virus in the monkeys (Fujii et al., 2018).

In contrast to both mouse and monkey models, VP1-145E does not appear to be associated with severe sequelae using human samples. Instead, amino acids 145Q had been observed in 2 out of 9 severe diseases (Chang et al., 2012). In addition, 145Q, $145 \mathrm{G}$, and 145R had been associated with virulent phenotype by analyzing 25 severe cases and 31 mild cases from the GenBank database ( $\mathrm{Li}$ et al., 2011). It has remained a discrepancy between mouse models and human samples whether VP1-145E and disease severity are associated with each other. Amino acid 145 of VP1 was thought to be involved in the binding between EVA71 and its entry receptor SCARB2 (scavenger receptor class B, member 2) (Victorio et al., 2016; van der Sanden et al., 2018). More recently, VP1-145 was shown to be related to binding to heparan sulfate (Tan et al., 2017; Fujii et al., 2018; Kobayashi et al., 2018, 2020). In this study using human clinical samples, we found five severity-associated mutations, including the $5^{\prime}$ UTR C580U, A707G, C709U, VP1-145(non-E), and VP1-280T. Interestingly, VP1-280T is located near the binding site with the VP2-EF loop and human SCARB2 receptor for viral entry (Zhou et al., 2019). Overall, our current results warrants further studies on the functional significance of these disease-associated mutations in animal models (Liao et al., 2014; Shih et al., 2018; Chang et al., 2019; Liou et al., 2019), once infectious cDNA clones can be successfully isolated from these patients in the future. Furthermore, our findings here could facilitate earlier detection based on the risk score in predicting severe cases infected with EV-A71 in clinical medicine. Hopefully, these novel mutations associated with disease severity could have a diagnostic potential in future epidemics of EV-A71.

\section{MATERIALS AND METHODS}

\section{Ethics Statement}

EV-A71 clinical isolates were kindly provided by Section of Clinical Virology and Molecular Diagnosis, Department of Laboratory Medicine, Changhua Christian Hospital, Taiwan.
Biosafety Committee approval number BSF 00520080030 from Academia Sinica, Taiwan.

\section{Disease Severity}

Clinical presentations of mild cases include herpangina or HFMD only. In addition to herpangina and HFMD, symptoms of severe cases include myoclonic jerks, meningitis, encephalitis, acute flaccid paralysis, pulmonary edema, cardiopulmonary failure, and death.

\section{Preparations of Cells and Viruses}

Human rhabdomyosarcoma (RD) cells (ATCC CCL-136) were cultured in DMEM (Dulbecco's modified Eagle medium) with $10 \%$ fetal bovine serum (FBS; HyClone) and $1 \%$ penicillinstreptomycin. Viral strains of EV-A71 were isolated from throat swabs of patients by the Section of Clinical Virology and Molecular Diagnosis, Department of Laboratory Medicine, Changhua Christian Hospital, Taiwan. Virus preparation was as described previously (Liao et al., 2014; Liou et al., 2016, 2019; Chang et al., 2019).

\section{RT-PCR and Sequencing}

Procedures for RT-PCR are as described elsewhere (Liao et al., 2014). The sequencing strategy and primer sequences are shown in Supplementary Figure 3A. 5' UTR and VP1 fragments were amplified using PCR primer pairs $\mathrm{F} 1$ and R4, F5 and R10, respectively. PCR-amplified DNA fragments were sequenced using the sequencing primers listed in Supplementary Figure 3B with ABI 3730XL DNA analyzer (PE Applied Biosystems, Foster City, CA, United States). Multiple sequence alignment was performed using the Clustal $\mathrm{W}$ multiple alignment program of the MegAlign software version 7.1.0 (DNASTAR, Madison, WI, United States).

\section{Binding Assay}

SH-SY5Y, HTB-10 and RD cells were seeded in 6 well plate $\left(1 \times 10^{6} /\right.$ well $)$ and cultured with Dulbecco's Modified Eagle medium (DMEM; Gibco) with 10\% fetal bovine serum (FBS; HyClone) and $1 \%$ penicillin-streptomycin (Gibco) at $37^{\circ} \mathrm{C}$ overnight. Culture medium was removed and cells were washed once with phosphate buffer saline (PBS) before incubation with EV-A71 virus VP1-280A or VP1-280T $($ M.O.I $=10$ ) at $4^{\circ} \mathrm{C}$ for $1 \mathrm{~h}$. Unbound virus was removed by washing with PBS three times. Total RNAs of cells were extracted with a WelPrep cell/tissue RNA kit (Wel-GENE), and were used for reverse transcription by a High-Capacity cDNA reverse transcription kit (Applied Biosystems). The synthetic cDNA was subjected to real-time quantitative PCR (qPCR) analysis by an ABI 7500 system with a Power SYBR green PCR master kit (both from Applied Biosystems). Specific primers for VP1 were CTAGAGGGTACCACCAATCC (forward) and AACCTGGCCAGTAGGAGT (reverse). The primer sequences of GAPDH (glyceraldehyde-3-phosphate dehydrogenase) were used as the internal control: ACCCAGAAGACTGTGGATGG (forward) and TCAGCTCAGGGATGACCTTG (reverse). The amounts of viral RNA were normalized to the levels of GAPDH. 
TABLE 1 | A summary of EV-A71 disease-associated mutations.

\begin{tabular}{|c|c|c|c|c|c|c|c|c|c|c|}
\hline \multicolumn{3}{|c|}{ Positions of mutation sites } & \multirow{3}{*}{$\begin{array}{l}\text { Location on } \\
\text { EV71 genome }\end{array}$} & \multicolumn{4}{|c|}{ Substitution mutations } & \multirow{3}{*}{$\begin{array}{l}\text { Virus } \\
\text { genotype }\end{array}$} & \multirow{3}{*}{$\begin{array}{l}\text { Patients and mouse } \\
\text { samples }\end{array}$} & \multirow[t]{3}{*}{ References } \\
\hline & & & & \multicolumn{2}{|c|}{ Nucleotide } & \multicolumn{2}{|c|}{ Amino acid } & & & \\
\hline $\begin{array}{l}\text { a.a. numbering in } \\
\text { mature viral } \\
\text { protein }\end{array}$ & $\begin{array}{l}\text { a.a. numbering in } \\
\text { precursor } \\
\text { polyprotein }\end{array}$ & $\begin{array}{l}\text { Nucleotide } \\
\text { number }\end{array}$ & & Severe & Mild & Severe & Mild & & & \\
\hline & & 580 & $5^{\prime}$ UTR & $U$ & C & & & B5 & 63 (27 severe vs. 36 mild) & Our own data \\
\hline & & 707 & $5^{\prime}$ UTR & $G$ & $A$ & & & B5 & 63 (27 severe vs. 36 mild) & \\
\hline & & 709 & $5^{\prime} \cup T R$ & $U$ & C & & & B5 & 63 (27 severe vs. 36 mild) & \\
\hline VP1 145 & & & VP1 & & & & Glu (E) & B5 & 63 (27 severe vs. 36 mild) & \\
\hline VP1 280 & & & VP1 & & & $\operatorname{Thr}(T)$ & Ala (A) & B5 & 63 (27 severe vs. 36 mild) & \\
\hline & & 150 & $5^{\prime}$ UTR & $G$ & $A, U$ & & & C4 and B5 & 18 (9 severe vs. 9 mild $)$ & Chang et al., 2012 \\
\hline & & 158 & $5^{\prime} \cup T R$ & C & U & & & $\mathrm{B} 1$ and $\mathrm{C} 2$ & $2(\mathrm{ICR} \text { mice })^{\star}$ & Yeh et al., 2011 \\
\hline & & 241 & $5^{\prime} \cup T R$ & C & $U$ & & & $\mathrm{C} 4 \mathrm{a}$ & 6 (1 severe vs. 5 mild) & Wen et al., 2013 \\
\hline & & 272 & $5^{\prime}$ UTR & $G$ & & & & C4 & 56 ( 25 severe vs. 31 mild) & Li et al., 2011 \\
\hline & & 488 & $5^{\prime} \cup T R$ & $u$ & & & & $\mathrm{C} 4$ & 56 ( 25 severe vs. 31 mild) & Li et al., 2011 \\
\hline & & 494 & $5^{\prime} \cup T R$ & $U$ & C & & & C2 & 1 (hSCARB2-Tg mice) $)^{*}$ & Chang et al., 2018 \\
\hline & & 571 & $5^{\prime}$ UTR & $A$ & $u$ & & & $\mathrm{C} 4 \mathrm{a}$ & 6 (1 severe vs. 5 mild) & Wen et al., 2013 \\
\hline & & 579 & $5^{\prime}$ UTR & $\mathrm{C}$ & $u$ & & & $\mathrm{C} 4 \mathrm{a}$ & 6 (1 severe vs. 5 mild) & Wen et al., 2013 \\
\hline & & 606 & $5^{\prime} \cup T R$ & $G$ & A & & & C4 and B5 & 18 (9 severe vs. 9 mild) & Chang et al., 2012 \\
\hline & & 700 & $5^{\prime} \cup T R$ & $A, U$ & & & & $\mathrm{C} 4$ & 56 (25 severe vs. 31 mild) & Li et al., 2011 \\
\hline VP2 149 & & & VP2 & $U$ & $A$ & Met(M) & Lys(K) & $\begin{array}{l}\text { C2 (mouse } \\
\text { adaptive strain) }\end{array}$ & $\begin{array}{l}1(\mathrm{ICR} \text { mice and Neuro-2a } \\
\text { cell })^{*}\end{array}$ & Huang et al., 2012 \\
\hline VP2 149 & & & VP2 & & & $\| e(l)$ & Lys $(K)$ & $\begin{array}{l}\text { B3 (mouse } \\
\text { adaptive strain) }\end{array}$ & $\begin{array}{l}1(\mathrm{BALB} / \mathrm{c} \text { mice and } \mathrm{CHO}) \\
\text { cells) }\end{array}$ & Chua et al., 2008 \\
\hline VP2 149 & & & VP2 & & & $\begin{array}{l}\text { Met(M) } \\
\| \mathrm{le}(\mathrm{l})\end{array}$ & Lys $(K)$ & $\begin{array}{l}\mathrm{B} 3, \mathrm{~B} 4, \mathrm{C} 1 \\
\mathrm{C} 2 \text {, and } \mathrm{C} 4\end{array}$ & $\begin{array}{l}5 \text { (PSGL1-expressing L929 } \\
\text { cell)* }\end{array}$ & Miyamura et al., 2011 \\
\hline VP2 149 & & & VP2 & & & $\| e(l)$ & Lys $(K)$ & B4 & $1(\text { ICR mice })^{\star}$ & Tee et al., 2019 \\
\hline VP1 97 & P662 & & VP1 & $G$ & $U$ & $\operatorname{Arg}(\mathrm{R})$ & Leu(L) & C & 1 (SH-SY5Y cell) ${ }^{*}$ & Cordey et al., 2012 \\
\hline VP1 104 & & & VP1 & $G$ & $A$ & Asp(D) & Asn(N) & $\mathrm{C} 2$ & 1 (hSCARB2-Tg mice) $^{*}$ & Chang et al., 2018 \\
\hline VP1 145 & & & VP1 & & & $\operatorname{Gln}(\mathrm{Q})$ & $\mathrm{Glu}(\mathrm{E})$ & C4 and B5 & 18 (9 severe vs. 9 mild) & Chang et al., 2012 \\
\hline VP1 145 & P710 & & VP1 & & & $\begin{array}{l}\text { Gly(G) } \\
\text { Gln(Q) } \\
\operatorname{Arg}(R)\end{array}$ & $\mathrm{Glu}(\mathrm{E})$ & $\mathrm{C} 4$ & 56 (25 severe vs. 31 mild) & Li et al., 2011 \\
\hline VP1 145 & & & VP1 & & & $\mathrm{Glu}(\mathrm{E})$ & $\begin{array}{l}\mathrm{G} \ln (\mathrm{Q}) \\
\mathrm{Gly}(\mathrm{G})\end{array}$ & $\mathrm{C} 2$ & 1 (hSCARB2-Tg mice) $^{*}$ & Chang et al., 2018 \\
\hline
\end{tabular}


TABLE 1 | Continued

\begin{tabular}{|c|c|c|c|c|c|c|c|c|c|c|}
\hline \multicolumn{3}{|c|}{ Positions of mutation sites } & \multirow{3}{*}{$\begin{array}{l}\text { Location on } \\
\text { EV71 genome }\end{array}$} & \multicolumn{4}{|c|}{ Substitution mutations } & \multirow{3}{*}{$\begin{array}{l}\text { Virus } \\
\text { genotype }\end{array}$} & \multirow{3}{*}{$\begin{array}{l}\text { Patients and mouse } \\
\text { samples }\end{array}$} & \multirow[t]{3}{*}{ References } \\
\hline & & & & \multicolumn{2}{|c|}{ Nucleotide } & \multicolumn{2}{|c|}{ Amino acid } & & & \\
\hline $\begin{array}{l}\text { a.a. numbering in } \\
\text { mature viral } \\
\text { protein }\end{array}$ & $\begin{array}{l}\text { a.a. numbering in } \\
\text { precursor } \\
\text { polyprotein }\end{array}$ & $\begin{array}{l}\text { Nucleotide } \\
\text { number }\end{array}$ & & Severe & Mild & Severe & Mild & & & \\
\hline VP1 145 & & & VP1 & $\mathrm{G}$ & $\mathrm{C}$ & $\mathrm{Glu}(\mathrm{E})$ & $\mathrm{G} \ln (\mathrm{Q})$ & $\begin{array}{l}\mathrm{C} 2 \text { (mouse } \\
\text { adaptive strain) }\end{array}$ & $\begin{array}{l}1(\text { ICR mice and Neuro-2a } \\
\text { cell) })^{\star}\end{array}$ & Huang et al., 2012 \\
\hline VP1 145 & & & VP1 & & & Glu(E) & Gly(G) & $\begin{array}{l}\text { B3 (mouse } \\
\text { adaptive strain) }\end{array}$ & $1(\mathrm{BALB} / \mathrm{c} \mathrm{mice})^{*}$ & Chua et al., 2008 \\
\hline VP1 145 & & & VP1 & & & Glu(E) & $\operatorname{Gly}(\mathrm{G})$ & $\mathrm{B} 4$ and $\mathrm{C} 2$ & 2 (cynomolgus macaque) & Fujii et al., 2018 \\
\hline VP1 145 & & & VP1 & & & $\mathrm{Glu}(\mathrm{E})$ & Gly(G) & $\mathrm{B} 2, \mathrm{~B} 4$, and $\mathrm{C} 2$ & 3 (hSCARB2-Tg mice) ${ }^{\star}$ & Kobayashi et al., 2018 \\
\hline VP1 145 & & & VP1 & & & $\mathrm{Glu}(\mathrm{E})$ & $\mathrm{G} \ln (\mathrm{Q})$ & B4 & $1(\text { ICR mice })^{*}$ & Tee et al., 2019 \\
\hline VP1 146 & & & VP1 & & & $\mathrm{Val}(\mathrm{V})$ & lle(l) & $\mathrm{C} 2$ & 1 (hSCARB2-Tg mice) $^{\star}$ & Chang et al., 2018 \\
\hline VP1 164 & P729 & & VP1 & & & $\mathrm{Glu}(\mathrm{E})$ & $A s p(D)$ & $\mathrm{C} 4$ & 56 (25 severe vs. 31 mild) & Li et al., 2011 \\
\hline VP1 170 & & & VP1 & & & $\operatorname{Val}(V)$ & $\mathrm{Ala}(\mathrm{A})$ & $\mathrm{C} 2$ & 10 (7 severe vs. 3 mild $)$ & McMinn et al., 2001 \\
\hline VP1 241 & & & VP1 & & & $\operatorname{Ser}(S)$ & $\operatorname{Leu}(\mathrm{L})$ & $\mathrm{C} 2$ & 1 (hSCARB2-Tg mice) $^{*}$ & Chang et al., 2018 \\
\hline \multirow[t]{2}{*}{ VP1 244} & & & VP1 & & & $\mathrm{Glu}(\mathrm{E})$ & Lys(K) & B4 & $1(\text { ICR mice })^{\star}$ & Tee et al., 2019 \\
\hline & P814 & & VP1 & & & $\operatorname{Val}(\mathrm{V})$ & $\| \mathrm{ll}(\mathrm{l})$ & C4a & 31 ( 16 severe vs. 15 mild) & Wen et al., 2013 \\
\hline \multirow[t]{3}{*}{$2 \mathrm{~A} 68$} & P930 & & $2 \mathrm{~A}$ & & & $\operatorname{Lys}(\mathrm{K})$ & $\begin{array}{l}\operatorname{Met}(M) \\
\operatorname{Arg}(R)\end{array}$ & $\mathrm{C} 4$ & 56 (25 severe vs. 31 mild) & Li et al., 2011 \\
\hline & $\mathrm{P} 1148$ & & $3 \mathrm{~A}$ & & & Val(M) & $\| e(l)$ & $\mathrm{C} 4 \mathrm{a}$ & 31 ( 16 severe vs. 15 mild) & Wen et al., 2013 \\
\hline & P1728 & & $3 \mathrm{C}$ & & & $\mathrm{Ala}(\mathrm{A})$ & $\begin{array}{l}\operatorname{Cys}(C) \\
\operatorname{Val}(\mathrm{V})\end{array}$ & $\mathrm{C} 4 \mathrm{a}$ & 31 ( 16 severe vs. 15 mild) & Wen et al., 2013 \\
\hline \multirow[t]{3}{*}{ 3D 251} & & & $3 \mathrm{D}$ & & & $\| \mathrm{le}(\mathrm{l})$ & $\operatorname{Thr}(T)$ & $\mathrm{C} 2$ & $\begin{array}{l}1(\mathrm{ICR} \text { mice and SK-N-SH } \\
\text { cell) })^{\star}\end{array}$ & Kung et al., 2010 \\
\hline & P1994 & & $3 D$ & & & Val(M) & $\| \mathrm{le}(1)$ & C4 & 6 ( 3 severe vs. 3 mild) & Chang et al., 2010 \\
\hline & & 7335 & $3^{\prime}$ UTR & $U$ & C & & & $\mathrm{C} 4 \mathrm{a}$ & 6 ( 1 severe vs. 5 mild $)$ & Wen et al., 2013 \\
\hline
\end{tabular}

*Indicates that these studies were based on cell lines or mouse samples. 


\section{Bioinformatics}

Discovery Studio Visualizer is from Dassault Systèmes BIOVIA Corp (2015), San Diego, CA United States. The PyMOL software is from PyMOL Molecular Graphics System, Version 1.8 Schrödinger, LLC.

\section{Statistical Analysis}

Relative EV-A71 binding assay were analyzed by Student's $t$-test. Mutation frequencies of viral genome were analyzed by the Chisquare test and the Fisher's Exact test. ${ }^{*} P<0.05$; $^{* *} P<0.001$.

\section{GenBank Accession Numbers}

VP1 sequences: MT348284 - MT348346; 5' UTR sequences: MT360921 - MT360983; full-length EV-A71 genome: MT360984 - MT360998.

\section{RESULTS}

By PCR amplification and sequencing, we compared the sequences of the $5^{\prime}$ UTR and the capsid protein VP1 in viral genomes isolated from clinical samples of 36 mild and 27 severe patients. Full-length sequences of viral genomes were also obtained from 7 severe and 8 mild patients. These patients were collected during an EV-A71 outbreak in Taiwan in 2008 (Liao et al., 2014). Except for the 5' UTR and VP1, we found no mutation associated with disease severity, based on the full-length genome sequences from 7 severe and 8 mild cases. At the $5^{\prime}$ UTR (nt 1 - 747), three mutations C580U, A707G, C709U, were found to occur frequently in severe patients $(7 / 27)$ (Chi-square $p=0.006$; Fisher Exact test $p=0.0166$ ) (Figure 1 and Supplementary Figure 1). The mutation C580U falls within the stem-loop VI structure, and remains to be investigated whether C580U could affect the cap-independent translation via the internal ribosomal entry site (IRES). Mutations A707G, C709U are located in the linker region between the stem-loop VI and the AUG initiation codon.

Capsid protein VP1 (891 nt) has been used as a standard reference for genotyping. As shown in Figures 2A,B, VP1145 (non-E) is strongly associated with severe cases $(26 / 27$, $96 \%)$, while VP1-145E is also associated with mild cases (12/36, 33\%) (Chi-square $p=0.004$; Fisher Exact test $p=0.0043$ ) (Supplementary Figure 2). These 26 VP1-145(non-E) severe cases include 145Q (16), 145G (9), and 145A (1). Neither $145 \mathrm{Q}$ alone nor $145 \mathrm{G}$ alone is associated with severe cases with statistical significance.

GenBank database collected EV-A71 sequences $(n=3653$, as of April, 2020) deposited at different times from different countries worldwide. For most of these GenBank sequences, no information is available regarding the degree of disease severity of their source patients from the sequence-donating laboratories. Here, we consider these pooled and non-stratified GenBank sequences as a convenient baseline for comparison with our data. It is striking to note that VP1-145(non-E) occurs only at a baseline frequency of $13 \%$ (481/3653) in the GenBank database (Figure 2B), including 145Q (256/3653,
7\%), 145G (197/3653, 5.4\%), 145A (16/3653,0.4\%), and 145R $(5 / 3653,0.1 \%)$. In contrast, VP1-145(non-E) occurs at a 7.4fold higher frequency $(96 \%, 26 / 27)$ in our severe cases. In general, EV-A71 infection caused mainly subclinical or mild symptoms, such as herpangina and HFMD (McMinn, 2002; Shih et al., 2018). Occasionally, it could cause severe disease manifestations, such as neurological disorders, cardiopulmonary failure, and death. The vast majority of VP1 sequences in the GenBank contains a VP1-145E (3172/3653, 87\%) (Figure 2B). This fact supports the idea that VP1-145E is preferentially associated with mild cases, and is entirely consistent with our current knowledge about the predominant subclinical or mild symptoms in EV-A71 natural infection. As will be further discussed below, our results of $145 \mathrm{E}$ in mild cases and 145(nonE) in severe cases, are exactly opposite to the previous results from animal models (Chua et al., 2008; Huang et al., 2012; Chang et al., 2018; Fujii et al., 2018; Kobayashi et al., 2018; Tee et al., 2019).

Unexpectedly, among those 7 severe cases containing $5^{\prime}$ UTR mutations, 6 out of 7 cases contain a novel alanine-to-threonine mutation at the VP1 position 280 (A280T) (Figure 2A). We found 99\% (3199/3231) of VP1 sequences in the GenBank contains a VP1-280A, and only $0.6 \%$ contains a VP1-280T $(20 / 3231)$. In contrast, $22 \%(6 / 27)$ in our severe cases contains a VP1-280T (Figure 2C and Supplementary Figure 2). This frequency of occurrence $(22 \%)$ is near 37 -fold higher than the baseline frequency $(0.6 \%)$ of the GenBank database.

EV-A71 can bind to SCARB2 or PSGL-1 (P-selectin glycoprotein ligand-1) receptors for entry (Nishimura et al., 2009; Yamayoshi et al., 2009). The structure of the binding complex of EV-A71 and SCARB2 had recently been resolved by cryoEM at 3.4 - angstron resolution (Zhou et al., 2019). Coincidentally, amino acid 280 of VP1 is located in the immediate neighborhood of the contact site between VP2 and the SCARB2 receptor (Figure 3A). A close-up view at the contact site in Figure 3B revealed the interaction between a VP2 loop turn (green) and the $\alpha 7$ helix of SCARB2 (orange). This loop turn of VP2 may be stabilized by a web-like interaction structure, which consists of multiple hydrogen bonds (black dashed lines) between VP1-281G, VP1-282D (blue), and VP2 135V - 141T (green). The VP1 mutation from alanine-to-threonine at amino acid 280 could generate an extra H-bond between VP1-280T and VP2-139T (red dashed line), which in turn could enhance the interaction between the virus and its SCARB2 entry receptor.

We compared the binding activities between VP1-280A and VP1-280T viruses with human rhabdomyosarcoma cell line $\mathrm{RD}$, and human neuroblastoma cell lines HTB10 and SHSY5Y (Figure 4A). No difference in their respective binding activities was detected between VP1-280A and its congenic (isogenic) VP1-280T using HTB10 or RD cells. However, VP1280T appeared to bind better to SH-SY5Y cells than VP1-280A. The expression levels of SCARB2 were similar in various host cell lines infected with VP1-280T or VP1-280A by Western blot analysis (Figure 4B). Therefore, it remains to be investigated why SH-SY5Y binds better with VP1-280T, rather than VP1-280A. We cannot exclude the possibility that SCARB2 polymorphism may exist between these cell lines tested for binding. 
A
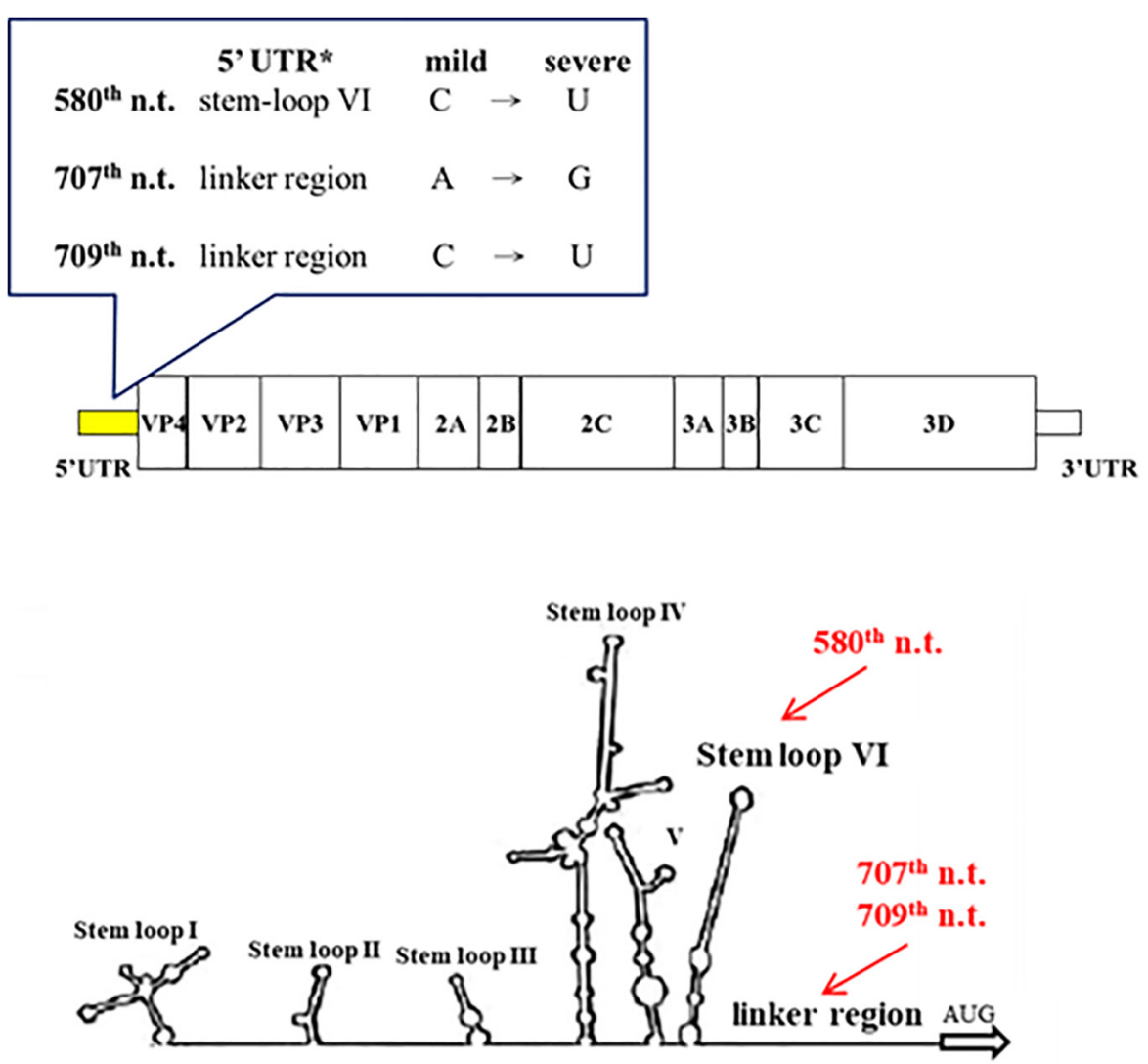

B

\begin{tabular}{ccc}
$\mathbf{5}^{\prime}$-UTR-580 & th \\
& $\mathrm{C}$ & $\mathbf{U}^{*}$ \\
\hline Mild cases (36) & $35(97 \%)$ & $\mathbf{1 ( 3 \% )}$ \\
Severe cases (27) & $20(74 \%)$ & $\mathbf{7 ( 2 6 \% )}$ \\
\hline
\end{tabular}

$5^{\prime}-$ UTR-707 $7^{\text {th }}$ nucleotide $\left(p=0.006^{*}\right)$

\begin{tabular}{ccc}
\hline & $\mathrm{A}$ & $\mathbf{G}^{*}$ \\
\hline Mild cases (36) & $35(97 \%)$ & $\mathbf{1 ( 3 \% )}$ \\
Severe cases (27) & $20(74 \%)$ & $7(\mathbf{2 6 \% )}$ \\
\hline
\end{tabular}

$5^{\prime}$-UTR-709'th nucleotide $\left(p=0.006^{*}\right)$

\begin{tabular}{ccc}
\hline & $\mathrm{C}$ & $\mathrm{U}^{*}$ \\
\hline Mild cases (36) & $35(97 \%)$ & $\mathbf{1 ( 3 \% )}$ \\
Severe cases (27) & $20(74 \%)$ & $\mathbf{7 ( 2 6 \% )}$ \\
\hline
\end{tabular}

FIGURE 1 | Association of disease severity with three point mutations in $5^{\prime}$ UTR. Genomic sequences of EV-A71 were compared between mild cases ( $n=36$ ) and severe cases $(n=27)$. (A) Three point mutations (red color) were found in the $5^{\prime}$ UTR: C580U, A707G, and C709U. In this 2D diagram of RNA fold, nt 580 is within stem-loop VI, and nt 707 and 709 are in the linker region. (B) Statistical analysis of these severity-associated UTR mutations. * $p$-value refers to the Chi-square statistical analysis ( $\chi 2=7.4574$ ) of the bolded columns. Fisher's Exact Test $(p=0.0166)$, odds ratio $=12.25(95 \% \mathrm{Cl}=1.4041 \sim 106.8733)$. See also Supplementary Figure 1. 


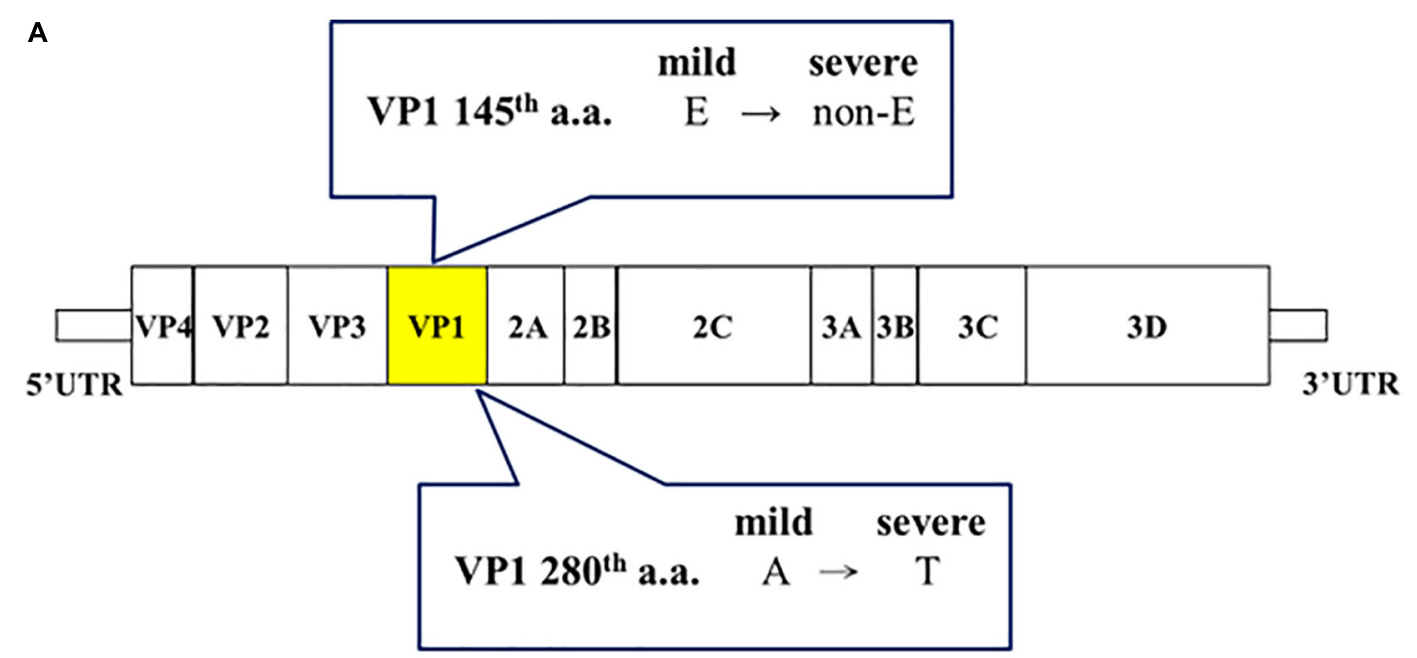

B

VP1-145 ${ }^{\text {th }}$ amino acid $\left(p=0.004^{*}\right)$

\begin{tabular}{ccc}
\hline & E (Glu) & non-E* \\
\hline Mild cases (36) & $12(33 \%)$ & $\mathbf{2 4}(\mathbf{6 7 \% )}$ \\
Severe cases (27) & $1(4 \%)$ & $\mathbf{2 6 ( 9 6 \% )}$ \\
\hline Genbank (3653) & $3172(87 \%)$ & $481(13 \%)$
\end{tabular}

C

\begin{tabular}{ccc}
\multicolumn{3}{c}{ VP1-280 } \\
& A (Ala) & T (Thr)* \\
\hline Mild cases (36) & $35(97 \%)$ & $\mathbf{1}(3 \%)$ \\
Severe cases (27) & $21(78 \%)$ & $\mathbf{6 ( 2 2 \% )}$ \\
\hline Genbank (3231) & $3199(99 \%)$ & $20(0.6 \%)$
\end{tabular}

FIGURE 2 | Capsid protein VP1-145(non-E) and VP1-280T are associated with disease severity in EV-A71 infected patients. (A) A summary cartoon of VP1 mutations associated with disease severity. (B) Statistical analysis revealed a strong association between VP1-145 (non-E) and severe cases. ${ }^{*} \mathrm{Chi}-$ square $(\chi 2=8.2708) p=0.004$; Fisher's Exact Test $(p=0.0043)$, odds ratio $=13(95 \% \mathrm{Cl}=1.5697 \sim 107.6669)$. (C) Statistical analysis revealed a significant association between VP1-280T and severe cases. ${ }^{*}$ Chi-square $(\chi 2=5.9063) p=0.015$; Fisher's Exact Test $(p=0.036)$, odds ratio $=10(95 \% \mathrm{Cl}=1.1247 \sim 88.9097)$. See also Supplementary Figure 2.

\section{DISCUSSION}

In literature, at least 10 mutations at the $5^{\prime}$ UTR have been associated with disease severity, including nt 150, 158, 241, 272, 488, 494, 571, 579, 606, and 700 (Table 1). None of these mutations in previous reports overlapped with our current mutations at nt 580, 707, and 709. The $5^{\prime}$ UTR is known to contain cis-elements important for both IRES-mediated capindependent translation and the replication origin for genome multiplication. While nucleotide 580 falls within the stemloop VI and IRES (Figure 1), nt 707 and 709 are in the linker region between IRES and the first AUG initiation codon. 
A

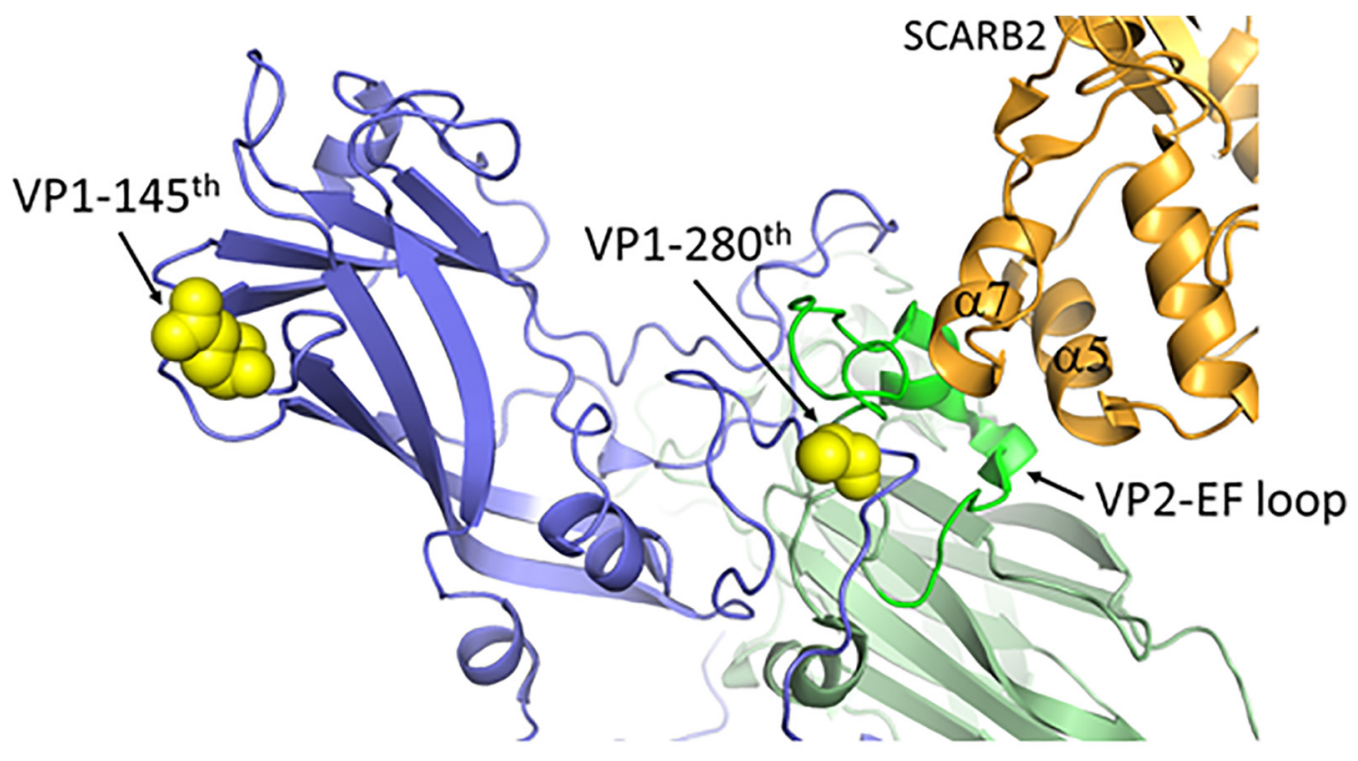

B
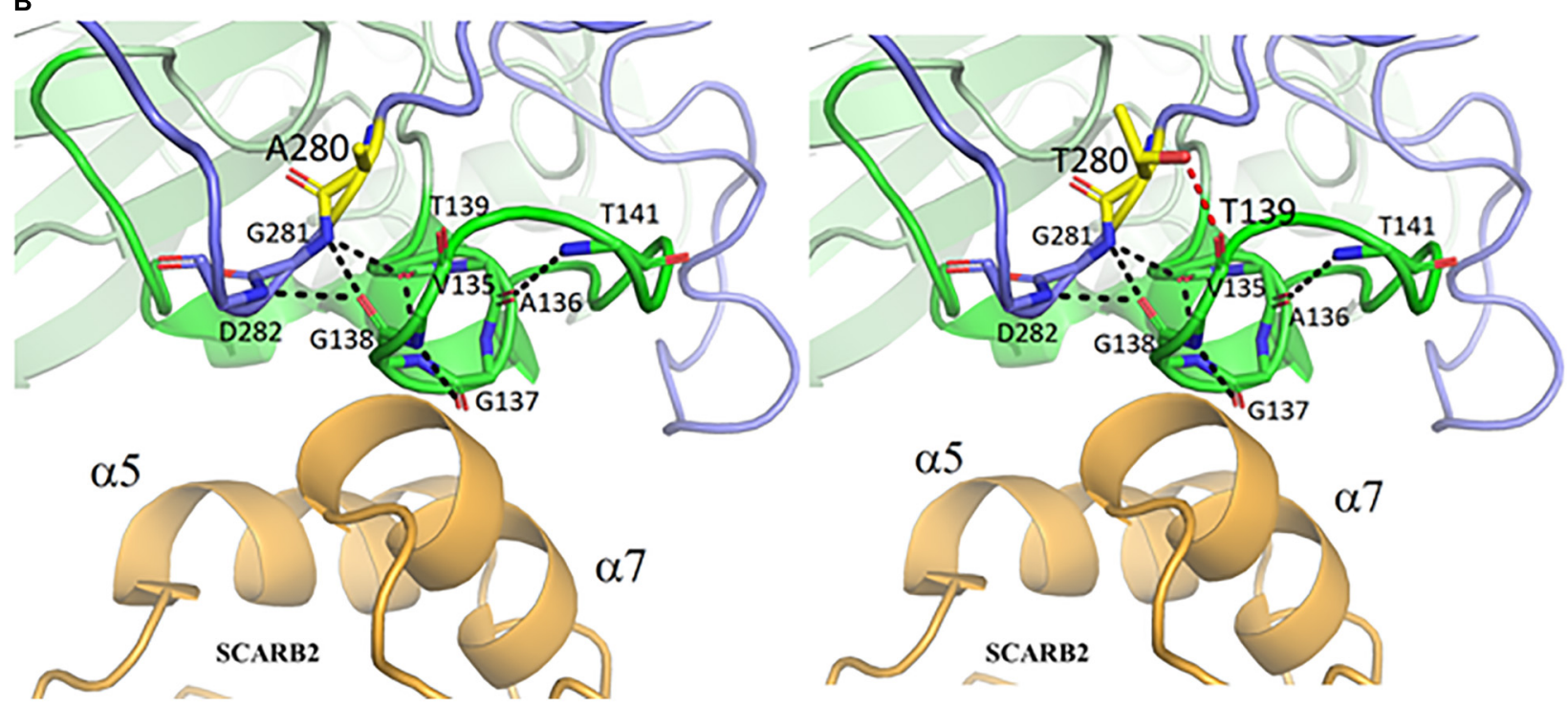

$\alpha 7$

FIGURE 3 | The mutant threonine of VP1-280T is located at the interaction hub between VP1, VP2 and the entry receptor hSCARB2. (A) VP1 amino acid 280, but not amino acid 145, is near the contact site between EV-A71 and hSCARB2, according to the cryoEM structure of the binding complex of VP1, VP2 and hSCARB2 at low pH (Zhou et al., 2019). PDB accession code: 6I2K. Orange, human SCARB2; Blue, VP1 capsid protein; Green, VP2-EF loop; Yellow, VP1 amino acids 145 and 280. (B) A loop turn of the VP2-EF loop (green) is in contact with the a7 helix of SCARB2 (orange). The backbone atoms of VP1 and the VP2 EF loop are represented as sticks with carbon atoms colored in light blue and green, respectively. This VP2 loop turn can be stabilized by a hydrogen-bonded network (black dashed lines) between the backbone oxygen and nitrogen atoms of VP1 G281-D282 and those of VP2 V135-T141. One de novo created hydrogen bond between the oxygen atom (hydroxyl group) of the mutant VP1-280T and the carbonyl group of VP2-139T is colored in a red dashed line. Residues A280 and T280 of VP1 are shown in sticks with carbon atoms in yellow. This figure is produced using Discovery Studio Visualizer and PyMOL (see section "Materials and Methods").

To investigate whether these novel 5' UTR mutations have any functional significance in IRES-mediated translation, we conducted reporter assays in human RD cells (data not shown). Although we observed no significant difference in the reporter activities between the WT and mutant $5^{\prime}$ UTR, it remains possible that these mutations could play a role in genome replication in viral life cycle.
In addition to $5^{\prime} \mathrm{UTR}$, severity-associated mutations had been reported to occur at VP1, VP2, 2A, and 3D (Table 1). It should be noted that some mutations, marked with a ${ }^{*}$ symbol in Table 1, were evaluated in mouse models. Therefore, they could reflect mouse-specific adaptive mutations, rather than bona fide naturally occurring mutations in human patients. For example, VP1-145E has been shown to contribute to viremia, lethality or 


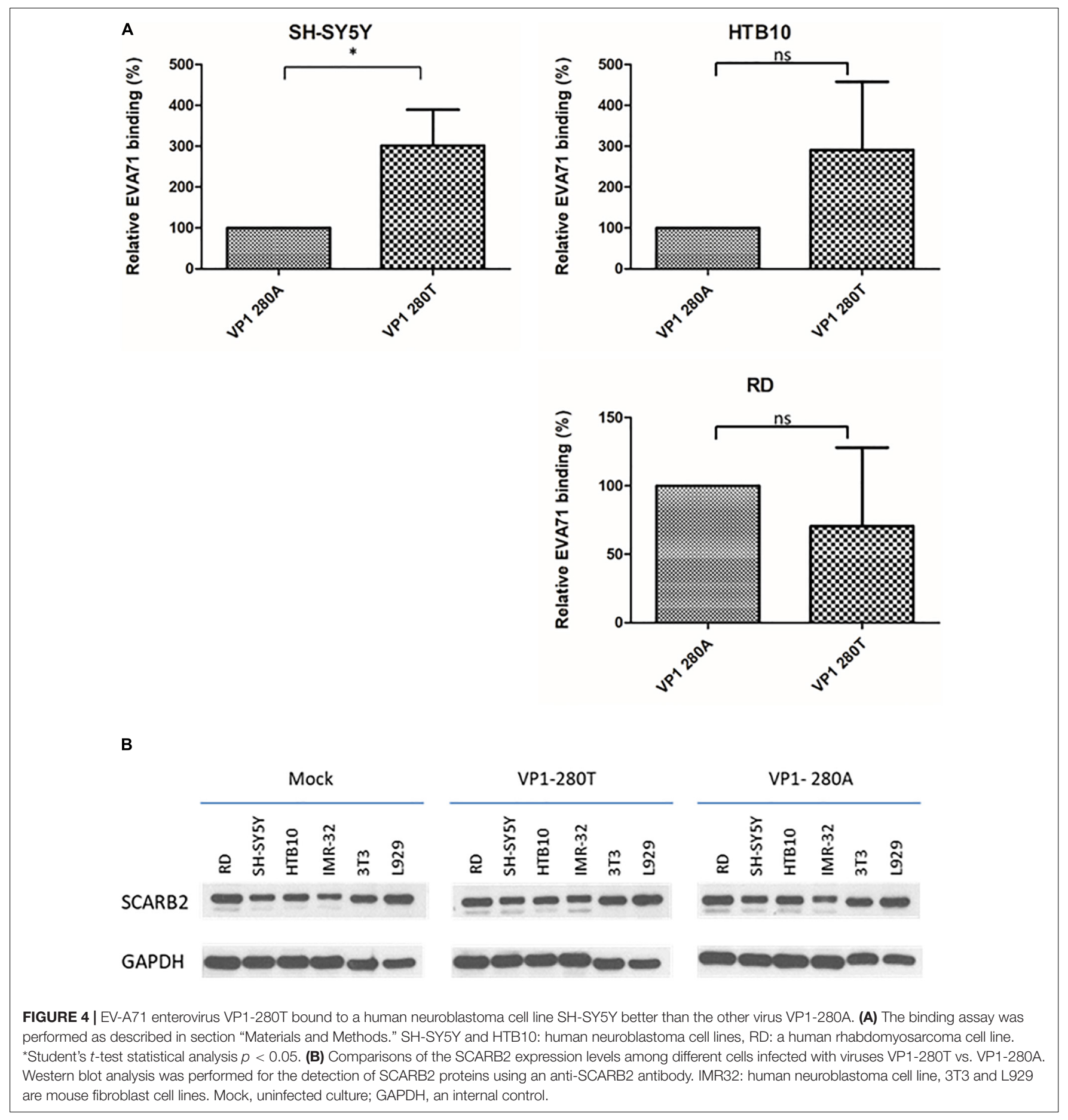

pathogenesis in animal models (Chua et al., 2008; Huang et al., 2012; Kataoka et al., 2015; Chang et al., 2018; Fujii et al., 2018; Kobayashi et al., 2018; Tee et al., 2019). However, in clinical samples, VP1-145E does not appear to be associated with severe cases (Figure 2B and further discussions below) (Li et al., 2011).

For example, a viral strain MP-26M from Australia was generated de novo by serial passages through newborn BALB/c mice (Chua et al., 2008). It harbored an artificial VP1-G145E adaptive mutation with increased virulence in mice. In another mouse-passaged strain MP4, it contained a mouse-adapted mutation VP1-Q145E. This VP1 Q145E mutation is absent in the parental clinical isolate from a Taiwanese patient, and exhibited increased infectivity in vitro and lethality in ICR mice (Huang et al., 2012). Conversely, consistent with these earlier reports, a viral strain EV-R containing a VP1-E145G mutation was found recently to become less virulent in hSCARB2 transgenic 
mice (Chang et al., 2018). Most recent studies from Japan also demonstrated that VP1-145E is associated with neurovirulence in suckling mice, hSCARB2 transgenic mice, and cynomolgus monkeys (Fujii et al., 2018; Kobayashi et al., 2018). Taken together, VP1-145E has always been shown to be a virulence determinant in mice. Unexpectedly, in our human samples, it is VP1-145(non-E) that is almost exclusively associated with human severe cases $(26 / 27,96 \%)$ (Figure 2B). Furthermore, in GenBank database, $87 \%(3172 / 3653)$ of the sequences contain a VP1-145E. In natural infection with EV-A71, mild symptoms are the most common clinical outcome. For example, in the 1998 epidemic in Taiwan, case severity rate is merely around $0.3 \%(405 / 129$, 106) (Ho et al., 1999). In China, between 2008 and 2012, a reported case severity rate is only around 1.1\% (Xing et al., 2014). Therefore, it is reasonable to believe that the vast majority of EV-A71 sequences (87\%) deposited in the GenBank, represents mainly virus isolates from the most common mild cases (99\%), rather than from the extremely rare severe cases $(0.3-1.1 \%)$.

Is it possible that this discrepancy between human and mouse studies in this VP1-145E related virulence, is actually related to the EV-A71 genotypic difference? A previous report found no correlation between genotypes and virulence ( $\mathrm{Li}$ et al., 2011). As summarized in Table 1, the viruses used in human VP1145 studies are of the genotypes B5 and C4 (Li et al., 2011; Chang et al., 2012), while the viruses used in mouse model studies are of genotypes C2, B2, B3, and B4 (Table 1; Chua et al., 2008; Huang et al., 2012; Chang et al., 2018; Fujii et al., 2018; Kobayashi et al., 2018). No common genotype has ever been used in both human and mouse studies. We consider it most likely that $145 \mathrm{E}$ is artificially selected from the viral adaptation in the mouse environment.

It is noteworthy that in our mild cases, 67\% (24/36) also contained a 145 (non-E) (Figure 2B). It is quite possible that VP1-145(non-E), by itself, is not sufficient, or not the only major determinant for in vivo virulence. Viral mutations other than VP1-145(non-E), such as VP1-280T, could also contribute to the pathogenesis. The potential linkage relationship of these severityassociated mutations is shown in Table 2. Among the 7 severe patients containing $5^{\prime}$ UTR mutations, 6 out of 7 severe cases also contain a VP1-A280T mutation. Finally, individual's age and host immunity are also major factors in pathogenesis (Liao et al., 2014; Liou et al., 2016, 2019; Shih et al., 2018). It cannot be excluded that some of the borderline severe cases (in the gray zone) may have been classified into the category of mild cases.

VP1 amino acid 145 has been considered as a key residue for binding to heparan sulfate and PSGL-1 receptor (Nishimura et al., 2013; Tan et al., 2017; Fujii et al., 2018; Tee et al., 2019; Kobayashi et al., 2020). While strain VP1-145G/Q can bind to PSGL-1, the viral strain VP1-145E cannot bind to PSGL-1 (Nishimura et al., 2013). Relative to the VP1-145Q virus, VP1-145E virus is a weak heparan-binder, yet correlated with increased virulence in animal models (Fujii et al., 2018; Kobayashi et al., 2018). It was therefore hypothesized that the VP1-145Q virus could be attenuated in mice by its better binding to heparan sulfate of the peripheral tissues (Fujii et al., 2018; Kobayashi et al., 2018). Heparan sulfate on the cell surface is a very common attachment site for many other viruses, including herpesvirus, human immunodeficiency
TABLE 2 | Linkage of EV-A71 virulent mutations in 27 severe cases.

\begin{tabular}{|c|c|c|c|c|c|}
\hline & \multicolumn{3}{|c|}{ 5'-UTR nucleotide \# } & \multicolumn{2}{|c|}{ VP1 amino acid \# } \\
\hline & 580 & 707 & 709 & 145 & 280 \\
\hline No. F1 & U & $G$ & $U$ & Gly & Thr \\
\hline No. F6 & U & G & U & Gly & Ala \\
\hline No. F7 & $U$ & G & $U$ & Gly & Thr \\
\hline No. F9 & U & $G$ & $U$ & Gln & Thr \\
\hline No. F17 & $U$ & G & $U$ & Glu & Thr \\
\hline No. F22 & $U$ & G & $U$ & Gln & Thr \\
\hline No. F23 & $U$ & G & $U$ & Gln & Thr \\
\hline No. 1 & C & A & C & Gln & Ala \\
\hline No. 5 & C & A & C & Gln & Ala \\
\hline No. 6 & C & A & C & Gln & Ala \\
\hline No. 26 & C & A & C & Gly & Ala \\
\hline No. F2 & C & A & C & Gly & Ala \\
\hline No. F3 & C & A & C & Gln & Ala \\
\hline No. F4 & C & A & C & Gln & Ala \\
\hline No. F5 & C & A & C & Gln & Ala \\
\hline No. F8 & C & A & C & Gly & Ala \\
\hline No. F10 & C & A & C & Gln & Ala \\
\hline No. F11 & C & A & C & Gln & Ala \\
\hline No. F12 & C & A & C & Gly & Ala \\
\hline No. F13 & C & A & C & Gln & Ala \\
\hline No. F14 & C & A & C & Gln & Ala \\
\hline No. F15 & C & A & C & Gln & Ala \\
\hline No. F16 & C & A & C & Gln & Ala \\
\hline No. F18 & C & A & C & Gly & Ala \\
\hline No. F19 & C & A & C & Gln & Ala \\
\hline No. F20 & C & A & C & Gly & Ala \\
\hline No. F21 & C & A & C & Ala & Ala \\
\hline
\end{tabular}

virus and hepatitis B virus (Shukla and Spear, 2001; Connell and Lortat-Jacob, 2013; Choijilsuren et al., 2017). It would be interesting to ask whether poor heparin-binding viruses other than EV-A71 can also predict virulence.

Using a RD-A cell line, Kobayashi et al. (2020) reported rapid and frequent selection and adaptation of heparan sulfatebinding variants, changing from VP1-145E to VP1-145Q/G. Is it possible that the tight association $(26 / 27,96 \%$ in Figure $2 B$ ) between disease severity and VP1-145(non-E), simply reflects a bias in cell culture? It will be ideal if one can compare the VP1 sequences before and after passages through the cell culture. However, in most cases, the amount of clinical samples are scarce, and not available for direct PCR amplification and sequencing. Overall, we consider it highly unlikely for the following reasons: First, we used the same RD cells to amplify EV-A71 from both severe $(n=27)$ and mild cases $(n=36)$. There is no reason that the same RD cells preferentially select for 145(nonE) variant, only when the virus is from severe cases, but not when the virus is from mild cases. Why should the $\mathrm{RD}$ cells discriminate between viruses originating from severe versus mild cases? Second, the phenomenon observed in the RD-A cell line (Kobayashi et al., 2020) may not necessarily be applicable to the $\mathrm{RD}$ cell line. Presumably, this RD-A cell line is a derivative of the 
RD cell line. Third, there are more than 3,000 entries of VP1 sequences in GenBank database. The vast majority (87\%) contained VP1-145E (Figure 2B). In epidemiological studies, 99\% of EV-A71 infected children are mild cases (Ho et al., 1999; Xing et al., 2014). In all studies on EV-A71 reported to date, the $\mathrm{RD}$ cell line, instead of the RD-A cell line, was always the most commonly used in literature (Table 1). It would be most informative in the future if $\mathrm{RD}$ and $\mathrm{RD}-\mathrm{A}$ cell lines will be compared side-by-side in the same experimental setting in the future.

In GenBank database, there are 20 EV-A71 sequences containing a VP1-280T mutation (Supplementary Table 1). Further examination of these $280 \mathrm{~T}$ variant sequences revealed that most of them are of genotype B5 from the 2008 epidemic in Taiwan, albeit two sequences are of genotype C1 from United Kingdom, and one is of genotype C4 from China. Therefore, while mutation VP1-280T is associated with disease severity of patients infected with genotype B5 (Figure 2C), it is likely that this $280 \mathrm{~T}$ mutation may be associated with severe cases infected with other genotypes, such as $\mathrm{C} 1$ and $\mathrm{C} 4$.

Recently, the initial attachment complex between EV-A71 and SCARB2 at low $\mathrm{pH}$ was visualized by cryoEM (Zhou et al., 2019). It reveals that SCARB2 binds EV-A71 on the southern rim of the canyon, rather than across the canyon as predicted previously (Chen et al., 2012; Dang et al., 2014; Zhang et al., 2017). This new structure suggests an allosteric mechanism for receptor binding, and the subsequent uncoating of EV-A71 in the low-pH lumen of endosome or lysosome. According to this complex structure, VP1-145 is far away from the contact site between SCARB2 and VP2 (Figure 3A). Interestingly, we found VP1-280 is in close proximity to SCARB2 and VP2 (Figure 3B). We entertain the possibility that VP1-280T could form hydrogen bonding with VP2-139T and help stabilize the VP2 interaction with SCARB2. This ternary complex could play an important role in the viral attachment and entry into the host cells. We found no consensus sequences for serine/threonine-kinase substrates around VP1-280T and VP2-139T. O-glycosylation at these residues cannot be excluded.

While VP1-145E does not bind to PSGL-1 receptor, VP1145Q/G was shown to bind to PSGL-1 (Nishimura et al., 2013). Unlike VP1-280, VP1-145 is far away from the SCARB2 binding site (Figure 3A). Taken together, we report here that VP1145(non-E) could be associated with an increased risk for disease severity, most likely via the PSGL-1 receptor-mediated entry pathway. In contrast, VP1-280T could contribute to virulence via a de novo created hydrogen bonding with the highly conserved VP2-139T. This novel hydrogen bonding could help stabilize a

\section{REFERENCES}

Bible, J. M., Iturriza-Gomara, M., Megson, B., Brown, D., Pantelidis, P., Earl, P., et al. (2008). Molecular epidemiology of human enterovirus 71 in the United Kingdom from 1998 to 2006. J. Clin. Microbiol. 46, 3192-3200. doi: 10.1128/jcm.00628-08

Chang, C. K., Wu, S. R., Chen, Y. C., Lee, K. J., Chung, N. H., Lu, Y. J., et al. (2018). Mutations in VP1 and 5'-UTR affect enterovirus 71 virulence. Sci. Rep. 8:6688.
VP2 loop turn by strengthening a web-like interaction structure of the VP1-VP2 complex, leading to more efficient infection via the SCARB2 receptor-mediated entry pathway. These severityassociated mutations might be useful for patient care as a diagnostic tool in predicting the course of disease progression.

\section{DATA AVAILABILITY STATEMENT}

The datasets presented in this study can be found in online repositories. The names of the repository and accession number(s) can be found below: https://www.ncbi.nlm.nih. gov/genbank/, accession numbers (MT360921-360998 and MT348284-348346).

\section{AUTHOR CONTRIBUTIONS}

C-SC, C-CL, and CS: experimental design. Y-YY, C-YL, and J-SL: virus isolates. C-SC and C-CL: conduct the experiments. C-SS, M-JH, C-SC, and CS: bioinformatics. CS and C-SC: writing. All authors: data analysis.

\section{FUNDING}

This work was supported by the Kaohsiung Medical University, Kaohsiung, Taiwan, Academia Sinica (AS-SUMMIT-109, MOST108-3114-Y-001-002, and AS-KPQ-109-BioMed), and Ministry of Science and Technology (MOST 106-2320-B-001-010, MOST 107-2321-B-001-028, MOST 107-0210-01-19-01, and MOST 109-2314-B-037-137), Taiwan.

\section{ACKNOWLEDGMENTS}

We thank the DNA Sequencing Core Facility (AS-CFII-108-115) and the Biosafety Level 3 Facility, Academia Sinica, Taiwan. We also thank Drs. Cathy Shen-Jang Fann and Chien-Hsiun Chen for the discussions on statistical analysis.

\section{SUPPLEMENTARY MATERIAL}

The Supplementary Material for this article can be found online at: https://www.frontiersin.org/articles/10.3389/fmicb. 2020.610568/full\#supplementary-material

Chang, C.-S., Liao, C.-C., Liou, A.-T., Chang, Y.-S., Chang, Y.-T., Tzeng, B.-H., et al. (2019). Enterovirus 71 targets the cardiopulmonary system in a robust oral infection mouse model. Sci. Rep. 9:11108.

Chang, G. H., Lin, L., Luo, Y. J., Cai, L. J., Wu, X. Y., Xu, H. M., et al. (2010). Sequence analysis of six enterovirus 71 strains with different virulences in humans. Virus Res. 151, 66-73. doi: 10.1016/j.virusres.2010.04.001

Chang, S. C., Li, W. C., Chen, G. W., Tsao, K. C., Huang, C. G., Huang, Y. C., et al. (2012). Genetic characterization of enterovirus 71 isolated from patients with 
severe disease by comparative analysis of complete genomes. J. Med. Virol. 84, 931-939. doi: $10.1002 /$ jmv.23287

Chen, P., Song, Z., Qi, Y., Feng, X., Xu, N., Sun, Y., et al. (2012). Molecular determinants of enterovirus 71 viral entry: cleft around GLN-172 on VP1 protein interacts with variable region on scavenge receptor B 2. J. Biol. Chem. 287, 6406-6420. doi: 10.1074/jbc.m111.301622

Choijilsuren, G., Jhou, R. S., Chou, S. F., Chang, C. J., Yang, H. I., Chen, Y. Y., et al. (2017). Heparin at physiological concentration can enhance PEG-free in vitro infection with human hepatitis B virus. Sci. Rep. 7:14461.

Chua, B. H., Phuektes, P., Sanders, S. A., Nicholls, P. K., and McMinn, P. C. (2008). The molecular basis of mouse adaptation by human enterovirus 71. J. Gen. Virol. 89, 1622-1632. doi: 10.1099/vir.0.83676-0

Connell, B. J., and Lortat-Jacob, H. (2013). Human immunodeficiency virus and heparan sulfate: from attachment to entry inhibition. Front. Immunol. 4:385. doi: $10.3389 /$ fimmu. 2013.00385

Cordey, S., Petty, T. J., Schibler, M., Martinez, Y., Gerlach, D., van Belle, S., et al. (2012). Identification of site-specific adaptations conferring increased neural cell tropism during human enterovirus 71 infection. PLoS Pathogens 8:e1002826. doi: 10.1371/journal.ppat.1002826

Cox, J. A., Hiscox, J. A., Solomon, T., Ooi, M. H., and Ng, L. F. P. (2017), Immunopathogenesis and Virus-Host interactions of enterovirus 71 in patients with hand. foot and mouth disease. Front. Microbiol. 8:2249. doi: 10.3389/fmicb. 2017.02249

Dang, M., Wang, X., Wang, Q., Wang, Y., Lin, J., Sun, Y., et al. (2014). Molecular mechanism of SCARB2-mediated attachment and uncoating of EV71. Protein Cell 5, 692-703. doi: 10.1007/s13238-014-0087-3

Feng, Z., Hensley, L., McKnight, K. L., Hu, F., Madden, V., Ping, L., et al. (2013). A pathogenic picornavirus acquires an envelope by hijacking cellular membranes. Nature 496, 367-371. doi: 10.1038/nature12029

Fujii, K., Sudaka, Y., Takashino, A., Kobayashi, K., Kataoka, C., Suzuki, T., et al. (2018). VP1 Amino acid residue 145 of enterovirus 71 Is a Key residue for its receptor attachment and resistance to neutralizing antibody during cynomolgus monkey infection. J. Virol. 92:e00682-18.

Ho, M., Chen, E. R., Hsu, K. H., Twu, S. J., Chen, K. T., Tsai, S. F., et al. (1999). An epidemic of enterovirus 71 infection in Taiwan. Taiwan enterovirus epidemic working group. New England J. Med. 341, 929-935. doi: 10.1056/ nejm199909233411301

Huang, S. W., Wang, Y. F., Yu, C. K., Su, I. J., and Wang, J. R. (2012). Mutations in VP2 and VP1 capsid proteins increase infectivity and mouse lethality of enterovirus 71 by virus binding and RNA accumulation enhancement. Virology 422, 132-143. doi: 10.1016/j.virol.2011.10.015

Huang, Y. P., Lin, T. L., Lin, T. H., and Wu, H. S. (2013). Antigenic and genetic diversity of human enterovirus 71 from 2009 to 2012. Taiwan. PLoS One 8:e80942. doi: 10.1371/journal.pone.0080942

Kataoka, C., Suzuki, T., Kotani, O., Iwata-Yoshikawa, N., Nagata, N., Ami, Y., et al. (2015). The role of VP1 amino acid residue 145 of enterovirus 71 in viral fitness and pathogenesis in a cynomolgus monkey model. PLoS Pathog. 11:e1005033. doi: 10.1371/journal.ppat.1005033

Kobayashi, K., Mizuta, K., and Koike, S. (2020). Heparan sulfate attachment receptor is a major selection factor for attenuated enterovirus 71 mutants during cell culture adaptation. PLoS Pathog. 16:e1008428. doi: 10.1371/journal.ppat. 1008428

Kobayashi, K., Sudaka, Y., Takashino, A., Imura, A., Fujii, K., and Koike, S. (2018). Amino acid variation at VP1-145 of enterovirus 71 determines attachment receptor usage and neurovirulence in human scavenger receptor b2 transgenic mice. J. Virol. 92:e00681-18.

Kung, Y. H., Huang, S. W., Kuo, P. H., Kiang, D., Ho, M. S., Liu, C. C., et al. (2010). Introduction of a strong temperature-sensitive phenotype into enterovirus 71 by altering an amino acid of virus 3D polymerase. Virology 396, 1-9. doi: 10.1016/j.virol.2009.10.017

Lee, K. M., Gong, Y. N., Hsieh, T. H., Woodman, A., Dekker, N. H., Cameron, C. E., et al. (2018). Discovery of Enterovirus A71-like nonstructural genomes in recent circulating viruses of the Enterovirus A species. Emerg. Microbes Infect. 7:111.

Lee, M. S., Lin, T. Y., Chiang, P. S., Li, W. C., Luo, S. T., Tsao, K. C., et al. (2010). An investigation of epidemic enterovirus 71 infection in Taiwan, 2008: clinical, virologic, and serologic features. Pediatr. Infect. Dis. J. 29, 1030-1034.

Li, R., Zou, Q., Chen, L., Zhang, H., and Wang, Y. (2011). Molecular analysis of virulent determinants of enterovirus 71. PLoS One 6:e26237. doi: 10.1371/ journal.pone. 0026237
Liao, C. C., Liou, A. T., Chang, Y. S., Wu, S. Y., Chang, C. S., Lee, C. K., et al. (2014). Immunodeficient mouse models with different disease profiles by in vivo infection with the same clinical isolate of enterovirus 71. J. Virol. 88, 12485-12499. doi: 10.1128/jvi.00692-14

Liou, A. T., Liao, C. C., Chou, S. F., Chang, Y. S., Chang, C. S., and Shih, C. (2019). Hypoxia and therapeutic treatment of EV-A71 with an immune modulator TLR7 agonist in a new immunocompetent mouse model. J. Biomed. Sci. 26:93.

Liou, A. T., Wu, S. Y., Liao, C. C., Chang, Y. S., Chang, C. S., and Shih, C. (2016). A new animal model containing human SCARB2 and lacking stat-1 is highly susceptible to EV71. Sci. Rep. 6:31151.

McMinn, P., Lindsay, K., Perera, D., Chan, H. M., Chan, K. P., and Cardosa, M. J. (2001). Phylogenetic analysis of enterovirus 71 strains isolated during linked epidemics in Malaysia. Singapore, and Western Australia. J. Virol. 75, 7732-7738. doi: 10.1128/jvi.75.16.7732-7738.2001

McMinn, P. C. (2002). An overview of the evolution of enterovirus 71 and its clinical and public health significance. FEMS Microbiol. Rev. 26, 91-107. doi: 10.1111/j.1574-6976.2002.tb00601.x

Miyamura, K., Nishimura, Y., Abo, M., Wakita, T., and Shimizu, H. (2011). Adaptive mutations in the genomes of enterovirus 71 strains following infection of mouse cells expressing human P-selectin glycoprotein ligand-1. J. Gen. Virol. 92, 287-291. doi: 10.1099/vir.0.022418-0

Nishimura, Y., Lee, H., Hafenstein, S., Kataoka, C., Wakita, T., Bergelson, J. M., et al. (2013). Enterovirus 71 binding to PSGL-1 on leukocytes: VP1-145 acts as a molecular switch to control receptor interaction. PLoS Pathogens 9:e1003511. doi: 10.1371/journal.ppat.1003511

Nishimura, Y., Shimojima, M., Tano, Y., Miyamura, T., Wakita, T., and Shimizu, H. (2009). Human P-selectin glycoprotein ligand-1 is a functional receptor for enterovirus 71. Nat. Med. 15:794. doi: 10.1038/nm.1961

Racaniello, V. R. (2006). One hundred years of poliovirus pathogenesis. Virology 344, 9-16. doi: 10.1016/j.virol.2005.09.015

Shih, C., Liao, C.-C., Chang, Y.-S., Wu, S.-Y., Chang, C.-S., and Liou, A.-T. (2018). Immunocompetent and immunodeficient mouse models for Enterovirus 71 pathogenesis and therapy. Viruses 10:674. doi: 10.3390/v10120674

Shukla, D., and Spear, P. G. (2001). Herpesviruses and heparan sulfate: an intimate relationship in aid of viral entry. J. Clin. Invest. 108, 503-510. doi: 10.1172/ jci200113799

Sin, J., Mangale, V., Thienphrapa, W., Gottlieb, R. A., and Feuer, R. (2015). Recent progress in understanding coxsackievirus replication, dissemination, and pathogenesis. Virology 484, 288-304. doi: 10.1016/j.virol.2015.06.006

Tan, C. W., Sam, I. C., Lee, V. S., Wong, H. V., and Chan, Y. F. (2017). VP1 residues around the five-fold axis of enterovirus A71 mediate heparan sulfate interaction. Virology 15, 79-87. doi: 10.1016/j.virol.2016.11.009

Tee, H. K., Tan, C. W., Yogarajah, T., Lee, M. H. P., Chai, H. J., Hanapi, N. A., et al. (2019). Electrostatic interactions at the five-fold axis alter heparinbinding phenotype and drive enterovirus A71 virulence in mice. PLoS Pathogens 15:e1007863. doi: 10.1371/journal.ppat.1007863

van der Sanden S. M., Sachs, N., Koekkoek, S. M., Koen, G., Pajkrt, D., Clevers, H., and Wolthers, K. C. (2018). Enterovirus 71 infection of human airway organoids reveals VP1-145 as a viral infectivity determinant. Emerg. Microbes. Infect. 7, 1-9. doi: 10.1038/s41426-018-0077-2

Victorio, C. B., Xu, Y., Ng, Q., Meng, T., Chow, V. T., and Chua, K. B. (2016). Cooperative effect of the VP1 amino acids $98 \mathrm{E}, 145 \mathrm{~A}$ and $169 \mathrm{~F}$ in the productive infection of mouse cell lines by enterovirus 71 (BS strain). Emerg. Microbes Infect. 5:e60.

Wen, H. L., Si, L. Y., Yuan, X. J., Hao, S. B., Gao, F., Chu, F. L., et al. (2013). Complete genome sequencing and analysis of six enterovirus 71 strains with different clinical phenotypes. Virol. J. 10:115. doi: 10.1186/1743-422x-10-115

Wu, W. H., Kuo, T. C., Lin, Y. T., Huang, S. W., Liu, H. F., Wang, J., et al. (2013). Molecular epidemiology of enterovirus 71 infection in the central region of Taiwan from 2002 to 2012. PLoS One 8:e83711. doi: 10.1371/journal.pone. 0083711

Xing, W., Liao, Q., Viboud, C., Zhang, J., Sun, J., Wu, J. T., et al. (2014). Hand, foot, and mouth disease in China, 2008-12: an epidemiological study. Lancet Infect. Dis. 14, 308-318.

Yamayoshi, S., Yamashita, Y., Li, J., Hanagata, N., Minowa, T., Takemura, T., et al. (2009). Scavenger receptor B2 is a cellular receptor for enterovirus 71. Nat. Med. 15, 798-801. doi: 10.1038/nm.1992

Yeh, M. T., Wang, S. W., Yu, C. K., Lin, K. H., Lei, H. Y., Su, I. J., et al. (2011). A single nucleotide in stem loop II of 5'-untranslated region contributes to 
virulence of enterovirus 71 in mice. PLoS One 6:e27082. doi: 10.1371/journal. pone. 0027082

Zeng, M., El Khatib, N. F., Tu, S., Ren, P., Xu, S., Zhu, Q., et al. (2012). Seroepidemiology of Enterovirus 71 infection prior to the 2011 season in children in Shanghai. J. Clin. Virol. 53, 285-289. doi: 10.1016/j.jcv.2011.12.025

Zhang, X., Yang, P., Wang, N., Zhang, J., Li, J., Guo, H., et al. (2017). The binding of a monoclonal antibody to the apical region of SCARB2 blocks EV71 infection. Protein Cell 8, 590-600. doi: 10.1007/s13238-017-0405-7

Zhou, D., Zhao, Y., Kotecha, A., Fry, E. E., Kelly, J. T., Wang, X., et al. (2019). Unexpected mode of engagement between enterovirus 71 and its receptor SCARB2. Nat. Microb. 4, 414-419. doi: 10.1038/s41564-018-0319-Z
Conflict of Interest: The authors declare that the research was conducted in the absence of any commercial or financial relationships that could be construed as a potential conflict of interest.

Copyright (c) 2021 Chang, Liao, Liou, Chou, Yu, Lin, Lin, Suen, Hwang and Shih. This is an open-access article distributed under the terms of the Creative Commons Attribution License (CC BY). The use, distribution or reproduction in other forums is permitted, provided the original author(s) and the copyright owner(s) are credited and that the original publication in this journal is cited, in accordance with accepted academic practice. No use, distribution or reproduction is permitted which does not comply with these terms. 